\title{
O processo ANAMMOX como alternativa para tratamento de águas residuárias, contendo alta concentração de nitrogênio
}

\author{
Marina B. Scheeren ${ }^{1}$, Airton Kunz $^{2}$, Ricardo L. R. Steinmetz ${ }^{2}$ \& Valderi L. Dressler ${ }^{3}$
}

\section{RESUMO}

O aumento da escala de produção agropecuária e agroindustrial traz, como consequência, a necessidade por alternativas para a mitigação dos impactos ambientais. As cadeias produtivas de proteína animal (ex.: suinocultura, bovinocultura e avicultura) produzem efluentes com elevada concentração de compostos nitrogenados. Neste contexto, o processo ANAMMOX (do inglês Anaerobic Ammonium Oxidation) se constitui em uma nova estratégia de alto desempenho visando remover compostos nitrogenados de águas residuárias, agropecuárias e agroindustriais, sob condições quimiolitoautotróficas. Este artigo apresenta uma revisão bibliográfica de trabalhos publicados nos últimos 15 anos sobre estudos deste processo, discutindo sua rota metabólica, demonstrando os micro-organismos envolvidos e os parâmetros de controle do processo, além de estudos desenvolvidos no Brasil e possíveis aplicações.

Palavras-chave: efluentes, dejetos de animais, tratamento biológico

\section{The ANAMMOX process as an alternative for treatment of water with high containing nitrogen}

\begin{abstract}
The increase in agriculture and agro-industrial scale production brings the necessity for alternatives to mitigate environmental impacts. The animal protein production chains (e.g. swine, cattle and poultry) produce effluents with high concentration of nitrogen compounds. In this context, the ANAMMOX (Anaerobic Ammonium Oxidation) process is a new strategy for nitrogen removal in a high rate from agricultural and agro-industrial wastewaters under chemolithoautotrophic conditions. This paper presents a literature review of papers published in the last 15 years about the ANAMMOX process, discussing their metabolic pathway, microorganisms, main control parameters as well as studies conducted in Brazil and application possibilities.
\end{abstract}

Key words: wastewater, animal manure, biological treatment

DTCA/UFSM, Av. Roraima, 1000, Cidade Universitária, Bairro Camobi, CEP 97105-900, Santa Maria, RS. Fone: (55) 3220 8254. E-mail: nina_bergoli@hotmail.com

${ }^{2}$ Embrapa Suínos e Aves, BR 153, Km 110, CEP: 89700-000, Concórdia, SC. Fone: (49) 3441 0400. E-mail: airton@cnpsa.embrapa.br; ricardo@cnpsa.embrapa.br

DQ/UFSM, Av. Roraima, 1000, Cidade Universitária, Bairro Camobi, CEP 97105-900, Santa Maria, RS. (55) 3220 8122. E-mail: valdres@quimica.ufsm.br 


\section{INTRODUÇÃO}

Devido ao crescimento populacional, à urbanização e à agregação de renda nos países em desenvolvimento, há um expressivo aumento e concentração na produção agroindustrial e agropecuária. Com isto, a pressão ambiental também tem crescido, haja vista que a quantidade de resíduos e efluentes tem acompanhado, de forma igualitária, a evolução dos processos produtivos. Neste sentido, principal atenção tem de ser dada aos efluentes das cadeias de produção de proteína animal, especialmente aos relacionados à produção, ao abate e processamento de suínos.

Em comparação com outras águas residuárias o nitrogênio presente nos efluentes da cadeia de produção de suínos ocorre em concentrações muito altas, o que torna difícil e onerosa sua recuperação ou remoção. Dentre as espécies de nitrogênio o $\mathrm{N}-\mathrm{NH}_{3}$ é um dos maiores componentes em águas residuárias da produção animal e agroindustrial. Portanto, necessita ser removido quando esses efluentes não têm possibilidade de valoração agronômica, ou seja, antes que sejam descartados em corpos d'água (van Dongen et al., 2001). Quando descartados inapropriadamente em ambientes aquáticos, efluentes com altas concentrações de nitrogênio podem causar efeitos adversos à microbiota aquática e, em contrapartida, alta demanda de oxigênio. Este efeito é caracterizado como eutrofização, resultado do excesso de nutrientes na água, possibilitando a proliferação excessiva de algas e bactérias que levam à consequente diminuição da qualidade do corpo receptor (Zhang et al., 2008).

Existem várias estratégias para redução do impacto ambiental de espécies nitrogenadas. Dentre elas, os processos de tratamento biológico para remoção de nitrogênio são os que apresentam menores custos de instalação e operação. Nas últimas décadas a descoberta de bactérias com atividade ANAMMOX (do inglês Anaerobic Ammonium Oxidation) tem revolucionado as barreiras evolutivas dos processos de tratamento de efluentes (Dapena-Mora et al., 2007). Tais bactérias possuem capacidade muito maior de transformação das espécies nitrogenadas presentes nos efluentes em nitrogênio gasoso $\left(\mathrm{N}_{2}\right)$ e demonstram crescente potencial para a aplicação no tratamento de efluentes agroindustriais, devido à sua alta eficiência e ao baixo custo.

Buscando entender melhor o processo ANAMMOX e as diferenças entre demais processos existentes na natureza, este manuscrito apresenta uma revisão da literatura com a síntese dos principais estudos ocorridos nos últimos 15 anos. O trabalho demonstra resultados de artigos científicos indexados e comunicações em eventos científicos. São apresentadas explicações sobre a rota metabólica, os micro-organismos envolvidos no processo, parâmetros relevantes para controle do processo, além de estudos recentes desenvolvidos no Brasil e discussões sobre prováveis aplicações aos efluentes agropecuários e agroindustriais.

\section{Processos CONVECIONAIS DE REMOÇÃO DE NITROGÊNIO}

Para remoção do nitrogênio em efluentes agropecuários e agroindustriais pode-se utilizar, basicamente, processos físicos, químicos e biológicos (Belli Filho et al., 2001; Kunz et al., 2009; Vivan et al., 2010).

Dentre os processos físicos a adsorção se mostra bastante eficiente para remover amônia de meios aquosos porém a utilização de resinas trocadoras de íons é economicamente inviável para o tratamento de efluentes (Pergher et al., 2005), mas alguns minerais naturais, como zeólitas e argilas, possuem elevada capacidade de trocar cátions. Em estudos recentes (Bolan et al., 2004; Hussain et al., 2006; Milan et al., 1997), mostraram a eficiência de adsorventes naturais na remoção de amônia de diferentes tipos de efluentes como, por exemplo, efluentes de laticínios e dejetos de suínos. Um estudo realizado por Higarashi et al. (2008), mostrou que a remoção da amônia presente em efluentes de suinocultura utilizando o processo de adsorção por zeólita natural (clinoptilolita-modernita) é influenciada pelo tamanho de partículas do adsorvente, sendo que a interferência ocasionada pela presença de outros cátions no efluente é intensificada nos adsorventes com tamanhos de partículas maiores. Este estudo também mostrou que é possível a reutilização da zeólita, após sua recuperação com solução de $\mathrm{NaCl}$ perdendo cerca de $10 \%$ da capacidade inicial de remoção.

Outra forma de remover compostos de nitrogênio é por processos químicos ou físico-químicos pela coprecipitação ou precipitação. Pastor et al. (2007) mostraram que é possível a remoção de fósforo e nitrogênio através de um processo biológico, complementado por um processo químico, através do qual ocorre a formação de estruvita $\left(\mathrm{MgNH}_{4} \mathrm{PO}_{4} \cdot 6 \mathrm{H}_{2} \mathrm{O}\right)$ e $\mathrm{Ca}_{3}\left(\mathrm{PO}_{4}\right)_{2}$. Apesar disto, na maioria das vezes os processos químicos estão limitados às condições de $\mathrm{pH}$ e características do efluente que, por sua vez, podem elevar os custos operacionais necessários para resultar em eficiência satisfatória.

Desta forma, a remoção de compostos nitrogenados de efluentes por processos biológicos é uma alternativa viável e com uso crescente devido a questões de favorecimento econômico com relação aos processos físicos e químicos.

Nas últimas décadas o surgimento de novos materiais permitiu a difusão do uso de biodigestores (tipo lagoa coberta), especialmente no tratamento de dejetos de animais (Belli Filho et al., 2001; Quadros et al., 2010). A utilização da digestão anaeróbia é bastante eficiente para a remoção de matéria orgânica (sobretudo carbono) paralelamente ao benefício da produção de biogás e energia. Porém a remoção de nitrogênio é ineficiente e são necessários tratamentos adicionais, sobremaneira em regiões de baixa disponibilidade de área para aproveitamento agronômico (Kunz et al., 2009; Vivan et al., 2010).

Apesar de pouco difundida no Brasil, a estratégia biológica convencional para a remoção de nitrogênio é a nitrificação/ desnitrificação, baseada na nitrificação aeróbia autotrófica e posterior desnitrificação em uma etapa anóxica e heterotrófica. Na primeira etapa o íon amônio é oxidado pelo oxigênio a nitrito e, posteriormente, a nitrato. Na segunda etapa o nitrito e o nitrato formados na etapa anterior são convertidos a nitrogênio gasoso. Este processo é geralmente mais eficiente em águas residuais com baixas concentrações de nitrogênio (Ahn, 2006). As reações que ocorrem no processo de nitrificação/ desnitrificação são mostradas nas Eqs. 1 a 4. 


$$
\begin{gathered}
\mathrm{NH}_{4}^{+}+1,5 \mathrm{O}_{2} \rightarrow \mathrm{NO}_{2}^{-}+2 \mathrm{H}^{+}+\mathrm{H}_{2} \mathrm{O} \\
\mathrm{NO}_{2}^{-}+0,5 \mathrm{O}_{2} \rightarrow \mathrm{NO}_{3}^{-} \\
2 \mathrm{NO}_{3}^{-}+10 \mathrm{H}^{+}+10 \mathrm{e}^{-} \rightarrow \mathrm{N}_{2}+2 \mathrm{HO}^{-}+4 \mathrm{H}_{2} \mathrm{O} \\
2 \mathrm{NO}_{2}^{-}+6 \mathrm{H}^{+}+6 \mathrm{e}^{-} \rightarrow \mathrm{N}_{2}+2 \mathrm{HO}^{-}+2 \mathrm{H}_{2} \mathrm{O}
\end{gathered}
$$

\section{OXIDAÇÃO ANAERÓBIA DE AMÔNIA (ANAMMOX)}

Durante muito tempo acreditou-se que a amônia só poderia ser oxidada em ambientes aeróbios. O conhecimento de que o nitrogênio amoniacal pudesse ser convertido sob condições anóxicas, veio de cálculos baseados na razão de Redfield em ecossistemas marinhos e de considerações teóricas com base em cálculos termodinâmicos (Richards, 1965; Broda, 1977; Jetten et al., 2004).

O processo de oxidação anaeróbia de amônia, ou simplesmente ANAMMOX (do inglês anaerobic ammonium oxidation), é uma das novas tecnologias para a remoção de nitrogênio. Este processo remove dois poluentes simultaneamente, amônio e nitrito, convertendo-os a nitrogênio gasoso (Zhang et al., 2008). A razão estequiométrica encontrada para o processo ANAMMOX está na faixa de amônio:nitrito de 1:1,32. (Strous et al., 1998).

O processo ANAMMOX é um tratamento biológico promissor para a redução de altas concentrações de nitrogênio em efluentes, considerando-se que transforma, de forma direta, compostos nitrogenados indesejados em gás nitrogênio (Dapena-Mora et al., 2007). Durante a última década vários trabalhos foram desenvolvidos no sentido de investigar o mecanismo dos micro-organismos responsáveis por essa oxidação e as aplicações do processo no tratamento de águas residuárias (Zhang et al., 2008).

\section{HisTÓRICO}

Aparentemente, muitos microbiologistas não sabiam que a oxidação anaeróbia da amônia era mais favorável que a nitrificação convencional que ocorre na presença de oxigênio. Foi baseado em cálculos termodinâmicos que, em 1977, Broda previu a existência de bactérias quimiolitoautotróficas (Jetten et al., 2001). No entanto,devido ao pouco conhecimento da época, ele relatou dificuldades para estabelecer a base dessas reações (Kuenen, 2008). Broda postulou, então, duas estequiometrias termodinamicamente possíveis para a oxidação da amônia na ausência de oxigênio, em que as razões molares teóricas de amônio: nitrito foram de 1:1 e 1:1,67.

Somente no final da década de 90 Strous et al. (1998) apresentaram uma relação estequiométrica para o processo ANAMMOX baseada no balanço de massa de culturas enriquecidas, cuja razão amônio:nitrito foi 1:1,31.
Duas décadas depois das observações de Broda (1977), o processo ANAMMOX foi observado, primeira vez, em um reator de nitrificação/desnitrificação que tratava o efluente de um reator anaeróbio em escala de laboratório (Ahn, 2006). Strous et al. (1999b) identificaram o organismo responsável pela remoção de nitrogênio e concluíram que se tratava de um tipo de bactéria do filo Planctomycete e que a taxa de crescimento da bactéria era relativamente baixa, cerca de onze dias para duplicação. Hoje se sabe que, para aplicar o processo ANAMMOX ao tratamento de águas residuárias, uma grande quantidade de inóculo é necessária (Isaka et al., 2006).

Até agora três gêneros principais de bactérias com atividade ANAMMOX já foram encontrados: Brocadia, Kuenenia e Scalindua (Dapena-Mora et al., 2007). As bactérias com atividade ANAMMOX são facilmente reconhecidas por sua baixa velocidade de duplicação e pela alta afinidade com os substratos (nitrito e amônio) (Zhang et al., 2008). Elas têm sido encontradas em águas residuais e sistemas naturais.

O filo Planctomycete consiste de onze gêneros (Pirellula, Rhodopirellula, Blastopirellula, Planctomyces, Gemmata, Isosphaera, Brocadia, Kuenenia, Scalindua, Anammoxoglobus e Jettenia asiática (Sittig \& Schlesner, 1993; Strous et al., 1999b; Kartal et al., 2007; Schierholt Neto, 2007).

Em um estudo realizado por Viancelli et al. (2009), analisouse a bactéria responsável pela atividade ANAMMOX em um reator experimental aclimatado com o lodo de anaeróbio de tratamento de dejetos de suínos. A atividade ANAMMOX foi previamente detectada por amplificação, clonagem, sequenciamento e análise filogenética do material coletado do reator. Os resultados deste estudo indicam um novo gênero de bactéria para o processo ANAMMOX relacionado com Planctomycete KSU-1 e Jettenia asiática. Este foi o primeiro estudo descrevendo a análise molecular da bactéria responsável pela atividade ANAMMOX que reportou diferenças filogenéticas da microbiota brasileira comparadas com as já descobertas em outras partes do mundo.

\section{O PROCESSO ANAMMOX E SUA ROTA METABÓLICA}

Os micro-organismos com atividade ANAMMOX têm uma fisiologia não muito comum, pois produzem energia a partir do consumo de amônia e na ausência de oxigênio (Ahn, 2006).

No processo ANAMMOX o nitrogênio amoniacal é convertido a nitrogênio gasoso por bactérias oxidadoras anaeróbias com o nitrito atuando como aceptor de elétrons, sob condições anóxicas. Uma provável rota metabólica da reação foi proposta primeiro por van de Graaf et al. (1997). Neste estudo, hidroxilamina foi considerada um composto intermediário da reação de redução do nitrito e a hidrazina um composto intermediário da reação entre hidroxilamina e o íon amônio(Figura 1).

Hidrazina é o composto formado pela oxidação do íon amônio com ajuda da hidrazina-hidrolase. A enzima hidrazina-hidrolase $(\mathrm{HH})$ atravessa a membrana celular e promove a reação de oxidação do amônio para formar hidrazina. A enzima hidrazinaoxidase (HZO), que está situada na membrana celular, na parte do anammoxosoma, catalisa a reação da hidrazina a nitrogênio 


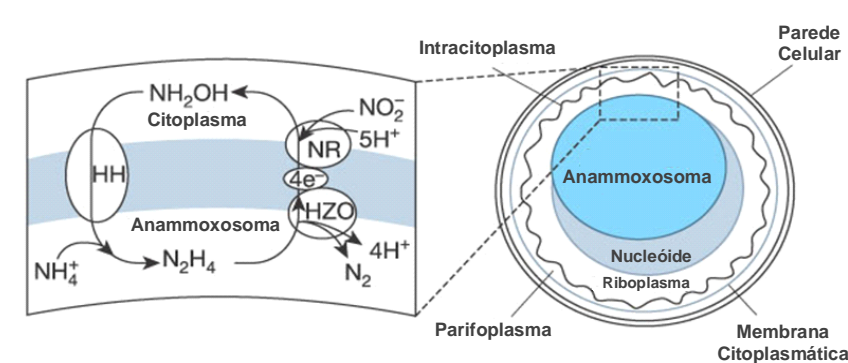

HH - HIDRAZINA-HIDROLASE; HZO - HIDRAZINA-OXIDASE; NR - NITRITO-REDUTASE Adaptada de Kuypers et al. (2003)

Figura 1. Rota metabólica do processo ANAMMOX, proposta primeiro por van de Graaf et al. (1997). A redução do nitrito a hidroxilamina é catalisada pela enzima nitrito-redutase (NR), que está situada na membrana celular, na parte do citoplasma

gasoso. Nesta reação os elétrons gerados são transferidos para a enzima nitrito-redutase e assim o ciclo continua (Zhu et al., 2008).

A reação química que ocorre no processo ANAMMOX é dada na Eq. 5.

$$
\begin{gathered}
1 \mathrm{NH}_{4}^{+}+1,32 \mathrm{NO}_{2}^{-}+0,066 \mathrm{HCO}_{3}^{-}+0,13 \mathrm{H}^{+} \rightarrow \\
1,02 \mathrm{~N}_{2}+0,26 \mathrm{NO}_{3}^{-}+0,066 \mathrm{CH}_{2} \mathrm{O}_{0,5} \mathrm{~N}_{0,15}+2,03 \mathrm{H}_{2} \mathrm{O}
\end{gathered}
$$

O produto principal da reação é o gás nitrogênio mas cerca de $10 \%$ da concentração de nitrogênio inicial são convertidos em nitrato (Ahn, 2006).

\section{FiguRAS DE MÉRITO E APLICAÇÕES DO PROCESSO}

Comparado com os processos convencionais de nitrificação/desnitrificação, o ANAMMOX tem a capacidade de remover cargas maiores de nitrogênio. Normalmente, a remoção de nitrogênio no processo ANAMMOX é acima de $2 \mathrm{~kg} \mathrm{~m}^{-3}$ de reator $\mathrm{d}^{-1}$ enquanto os processos convencionais (nitrificação/desnitrificação) operam com cargas cerca de 10 vezes menores. Tang et al. (2011) demonstraram resultados de remoção de 74,3 a $76,7 \mathrm{~kg} \mathrm{~m}^{-3}$ de reator $\mathrm{d}^{-1}$ em reatores de escala de bancada e com curto tempo de retenção hidráulica.

Além disso, o processo ANAMMOX ocorre pela ação de micro-organismos quimiolitoautotróficos, que não necessitam de carbono orgânico como fonte de energia (Zhu et al., 2008). O processo ANAMMOX apresenta economia no tamanho de reatores além de consumir cerca de $60 \%$ menos energia quando comparado ao processo con vencional (não necessita aeração). Também economiza custos com o tratamento do lodo em função do baixo crescimento celular - cerca de $0,11 \mathrm{~g} \mathrm{SSV} \mathrm{g}^{-1}$ $\mathrm{N}-\mathrm{NH}_{4}^{+}$(Isaka et al., 2006).

A conversão a nitrogênio é mais eficiente no processo ANAMMOX, pois transforma dois compostos nitrogenados, o íon amônio e o íon nitrito em nitrogênio gasoso, e faz um "atalho" comparado com o processo de nitrificação/ desnitrificação, como representado na Figura 2.

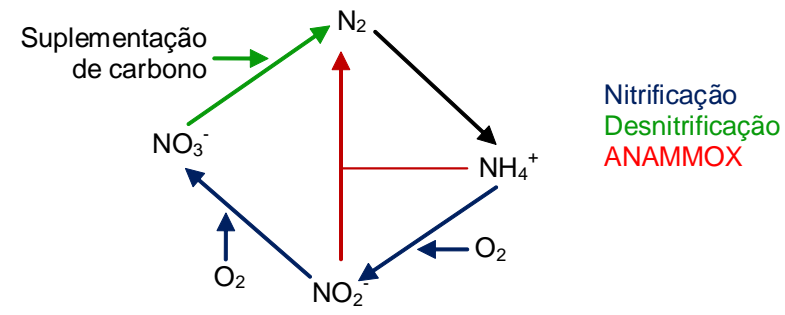

Figura 2. Ciclo simplificado do nitrogênio (Nitrificação, Desnitrificação e ANAMMOX)

\section{VARIÁVEIS DO PROCESSO}

Deve-se ter o controle de algumas variáveis de processo para se alcançar seu máximo rendimento, através de:

Configuração do reator: Em consequência da baixa taxa de crescimento dos micro-organismos com atividade ANAMMOX, recomendam-se reatores com configurações que diminuam o arraste de biomassa. Strous et al. (1998); Zhu et al., (2008) concluíram que sistemas de biofilmes e reatores de batelada sequencial (SBR, do inglês Sequencial Batch Reactor) são os mais indicados para o processo ANAMMOX.

Agnes et al. (2008) utilizaram, em seu estudo, um reator tubular de vidro, operado em fluxo pistão, totalmente isolado de oxigênio em cujo interior foi introduzido, de forma uniforme, um meio suporte polimérico não biodegradável, em forma de rede.

Concentração de oxigênio dissolvido (OD): Considerando que o processo ANAMMOX se processa em condições anóxicas, baixas concentrações de oxigênio no meio já podem interferir na eficiência do processo. Quando a concentração de OD não for suficiente para provocar a inibição total do processo, poderá provocar a inibição parcial ou até mesmo provocar a competição entre bactérias aeróbias e anaeróbias oxidadoras de amônio diminuindo, assim, a reação de remoção de nitrogênio pelo processo ANAMMOX. Strous et al. (1997a) demonstraram que a atividade da bactéria ANAMMOX sofrerá uma inibição temporária se a concentração de OD for até $0,2 \mathrm{mg} \mathrm{L}^{-1}$ e que esta inibição pode ser revertida sobre condições anóxicas. Com concentrações de OD entre $0,2-1.0 \mathrm{mg} \mathrm{L}^{-1}$, a bactéria sofre inibição completa.

Concentração do substrato: Os substratos amônio $\left(\mathrm{NH}_{4}^{+}\right)$e nitrito $\left(\mathrm{NO}_{2}^{-}\right)$e até mesmo o subproduto nitrato $\left(\mathrm{NO}_{3}^{-}\right)$, também podem provocar certa inibição no processo, dependendo da concentração em que se encontram no meio. As concentrações em que tais compostos provocam a inibição ou diminuição da eficiência do processo ANAMMOX, variam muito. Isto ocorre em virtude da quantidade de substrato de que o processo necessita pois, para que haja a reação sem haver a inibição, depende da espécie de bactéria utilizada, do tipo de reator, do tipo de alimentação e das condições físico-químicas oferecidas ao processo, dentre outros (Zhu et al., 2008).

Um sistema indicado por Schierholt Neto (2007) e composto por um reator tubular com suporte de material plástico para a imobilização da biomassa a uma temperatura de $35 \pm 2{ }^{\circ} \mathrm{C}$, foi 
inoculado com o lodo de uma lagoa anaeróbia alimentada com dejeto de suíno. O início da inibição do processo ANAMMOX por nitrito foi verificado a uma concentração de $140 \mathrm{mg} \mathrm{L}^{-1} \mathrm{de}$

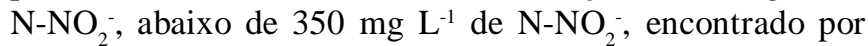
Dapena-Mora et al. (2007), ou seja, concentração capaz de inibir em $50 \%$ a atividade máxima dos micro-organismos ANAMMOX. Strous et al. (1999b) encontraram inibição por nitrito a uma concentração de $100 \mathrm{mg} \mathrm{L}^{-1}$. Esta alta variabilidade encontrada na inibição por nitrito é função da característica do reator e da biomassa, que pode causar diferentes níveis de proteção e adaptação dos micro-organismos (Egli et al., 2003).

Segundo Strous et al. (1999a) e Dapena-Mora et al. (2007), o íon amônio só passa a ser inibidor em concentrações muito elevadas, da ordem de $700 \mathrm{mg} \mathrm{N}-\mathrm{NH}_{4}^{+} \mathrm{L}^{-1}$. Jetten et al. (1999) mostram que amônio e nitrato provocam uma pequena inibição reversível no processo quando suas concentrações globais estão por volta de $1000 \mathrm{mg} \mathrm{N}-\mathrm{NH}_{4}^{+} \mathrm{L}^{-1}$.

Biomassa: Ni et al. (2010) propuseram uma nova estratégia para aumentar a carga de nitrogênio inicial do processo ANAMMOX e reduziram o tempo de enriquecimento e inibição da biomassa ANAMMOX através da interação dessas bactérias com grânulos metanogênicos inativos.

Em recente publicação, Tang et al. (2011) demonstraram resultados de remoção superiores a $70 \mathrm{~kg} \mathrm{~m}^{-3}$ de reator $\mathrm{d}^{-1}$ utilizando reatores do tipo UASB, em escala de bancada, com curtos tempos de retenção hidráulica (menor que $7 \mathrm{~h}$ ) e utilizando alta concentração de bactérias (entre 71,8 a 112,1 mg de polissacarídeos $\mathrm{gSSV}^{-1}$ e entre 164,4 a 298,2 $\mathrm{mg}$ de proteínas $\mathrm{gSSV}^{-1}$ ).

Potencial hidrogeniônico (pH): Faixa de $\mathrm{pH}$ fortemente ácido ou fortemente básico pode causar inibição completa do processo por promover hidrólise da membrana celular e cessar processos metabólicos vitais para as bactérias. A disponibilidade ou inibição pelo substrato também é influenciada pelo $\mathrm{pH}$. A percentagem de amônia e nitrito disponível nos efluentes a serem tratados é significativamente influenciada pelo $\mathrm{pH}$ em razão do deslocamento do equilíbrio químico dessas espécies (De Prá et al. 2010). A faixa de pHideal para este processo varia, dependendo do tipo de bactéria, mas geralmente o $\mathrm{pH}$ adequado se situa entre 7,7 e 8,3, com máxima taxa de reação em pH 8,0 (Strous et al.1997a).

Alcalinidade: A alcalinidade no processo ANAMMOX é fornecida pelo íon bicarbonato $\left(\mathrm{HCO}_{3}^{-}\right)$. Este íon faz parte da estequiometria da reação proposta por Strous et al. (1998) e precisa estar presente no meio reacional para que o processo ocorra. A alcalinidade exerce papel importante de tampão do meio, suavizando mudanças de $\mathrm{pH}$ no decorrer da reação, evitando que intermediários tóxicos ao processo se formem inibindo, parcial ou totalmente, os micro-organismos, com a atividade ANAMMOX.

Temperatura: A temperatura é fator significativo para o crescimento celular e atividade metabólica. Normalmente, quanto maior a temperatura maior é a multiplicação celular mas temperaturas muito altas acabam inibindo irreversivelmente as bactérias, por provocarem a lise celular. Cada tipo de micro- organismo tem sua temperatura ideal de desenvolvimento. A energia de ativação (Ea) do processo ANAMMOX foi calculada por Strous et al. (1997b) em um valor de $70 \mathrm{KJ} \mathrm{mol}^{-1}$. A temperatura de atuação do processo ANAMMOX está na faixa de 20 a $43{ }^{\circ} \mathrm{C}$, com o ótimo em $40 \pm 3{ }^{\circ} \mathrm{C}$ (Strous et al., 1999a).

\section{AgENTES INIBIDORES DO PROCESSO ANAMMOX}

Dapena-Mora et al. (2007), testaram os efeitos tóxicos de sais, matéria orgânica, fosfatos e sulfetos, utilizando concentrações otimizadas dos substratos, de $70 \mathrm{mg} \mathrm{L}^{-1}$ de nitrogênio $\left(\mathrm{NH}_{4}^{+} \mathrm{e} \mathrm{NO}_{2}^{-}\right)$. Nesses experimentos os autores constataram que sais como o cloreto de sódio $(\mathrm{NaCl})$ e cloreto de potássio $(\mathrm{KCl})$ começam a inibir o processo ANAMMOX em concentrações de $100 \mathrm{mmol} \mathrm{L}^{-1}$ e que, nesta mesma concentração, o sulfato de sódio $\left(\mathrm{Na}_{2} \mathrm{SO}_{4}\right)$ promove cerca de $80 \%$ de inibição. Já a matéria orgânica (testada com acetato de sódio) apresenta uma inibição de $50 \%$ na atividade da biomassa com concentração de $35 \mathrm{mmol} \mathrm{L}{ }^{-1}$ de acetato (o que corresponde a $840 \mathrm{mg} \mathrm{L}^{-1}$ de carbono). O efeito de fosfatos foi testado com fosfato de potássio diidrogenado $\left(\mathrm{KH}_{2} \mathrm{PO}_{4}\right)$ e uma inibição completa da atividade ANAMMOX foi observada com concentração de $25 \mathrm{mmol} \mathrm{L}^{-1}$ de fosfato, correspondendo a 775 $\mathrm{mg} \mathrm{L}^{-1}$ de fósforo. $\mathrm{O}$ efeito de sulfetos foi testado com sulfeto de sódio $\left(\mathrm{Na}_{2} \mathrm{~S}\right)$ e, com uma concentração de apenas $0,5 \mathrm{mmol}$ $\mathrm{L}^{-1}$ de sulfeto (16 $\mathrm{mg} \mathrm{L}^{-1}$ ), a atividade da biomassa reduziu a $20 \%$.

Um estudo para identificar a faixa de DQO (demanda química de oxigênio) e a razão DQO: nitrogênio que afeta o processo ANAMMOX, foi realizado por Chamchoi et al. (2008). Três reatores UASB (do inglês Upflow Anaerobic Sludge Blanket) de $200 \mathrm{~mL}$ foram inoculados com lodo anaeróbio granular (SST de $15 \mathrm{~g} \mathrm{~L}^{-1}$ ) e $40 \mathrm{mLde}$ um lodo ANAMMOX (SST de $200 \mathrm{mg} \mathrm{L}^{-1}$ ) de um reator SBR enriquecido durante três meses. Os reatores foram alimentados continuamente, com efluente sintético, a uma temperatura de $35{ }^{\circ} \mathrm{C}$ e um TRH (tempo de retenção hidráulico) de dois dias. A concentração de amônio, nitrito e nitrato no afluente foi de 40,50 e $50 \mathrm{mg} \mathrm{L}^{-1}$ de nitrogênio, respectivamente. A faixa de variação da concentração da DQO foi de $100 \mathrm{a} 400 \mathrm{mg} \mathrm{L}^{-1}$, sendo dividida nos três reatores: UASB 1 (100-200 mg L-1), UASB 2 (200-300 mg L L $^{-1}$ e UASB 3 (300-400 $\mathrm{mg} \mathrm{L}^{-1}$ ), e a razão DQO:nitrogênio de 0,9, 0,4 e 2,0, respectivamente. $O$ estudo demonstrou uma operação concorrente dos processos ANAMMOX e desnitrificação. A supressão da atividade ANAMMOX foi observada pelo monitoramento da eficiência do processo, que ocorreu a uma concentração de DQO na faixa de $300 \mathrm{mg} \mathrm{L}^{-1}$ ou razão DQO:N, de aproximadamente 2,0.

\section{Controle OPERACIONAL DOS REATORES}

\section{Obtenção dos coeficientes estequiométricos para a reação global}

A determinação dos coeficientes estequiométricos é muito importante para o processo ANAMMOX pois, a partir desses dados, é realmente possível acompanhar o desempenho do 
processo e comprovar se a reação ANAMMOX está ocorrendo. Se os coeficientes estequiométricos calculados forem muito diferentes dos sugeridos na literatura (Strous et al., 1998), significa que pode haver interferência de algum dos parâmetros de controle ou, até mesmo, de fatores externos, que podem promover uma outra rota para a oxidação da amônia, como a nitrificação parcial ou total.

Para o cálculo dos coeficientes estequiométricos considerase que nas equações o componente íon amônio possui coeficiente 1,0. Desta forma e de acordo com as Eqs. 6 a 8, os demais coeficientes podem ser determinados como segue (Schierhold Neto, 2007):

Coeficiente $\mathrm{N}-\mathrm{NH}_{4}^{+}=\frac{\text { Carga de } \mathrm{NH}_{4}^{+} \text {removida no dia }\left(\mathrm{mg} \mathrm{L}^{-1} \mathrm{~d}^{-1} \mathrm{~N}-\mathrm{NH}_{4}^{+}\right)}{\text {Carga de } \mathrm{NH}_{4}^{+} \text {removida no dia } \mathrm{z}\left(\mathrm{mg} \mathrm{L}^{-1} \mathrm{~d}^{-1} \mathrm{~N}-\mathrm{NH}_{4}^{+}\right)}$

Coeficiente $\mathrm{N}-\mathrm{NO}_{2}^{-}=\frac{\text { Carga de } \mathrm{NO}_{2}^{-} \text {removida no dia } \mathrm{z}\left(\mathrm{mg} \mathrm{L}^{-1} \mathrm{~d}^{-1} \mathrm{~N}-\mathrm{NO}_{2}^{-}\right)}{\text {Carga de } \mathrm{NH}_{4}^{+} \text {removida no dia }\left(\mathrm{mg} \mathrm{L}^{-1} \mathrm{~d}^{-1} \mathrm{~N}-\mathrm{NH}_{4}^{+}\right)}$

Coeficiente $\mathrm{N}-\mathrm{NO}_{3}^{-}=\frac{\text { Carga de } \mathrm{NO}_{3}^{-} \text {removida no dia } \mathrm{z}\left(\mathrm{mg} \mathrm{L}^{-1} \mathrm{~d}^{-1} \mathrm{~N}-\mathrm{NO}_{3}^{-}\right)}{\text {Carga de } \mathrm{NH}_{4}^{+} \text {removida no dia } \mathrm{z}\left(\mathrm{mg} \mathrm{L}^{-1} \mathrm{~d}^{-1} \mathrm{~N}-\mathrm{NH}_{4}^{+}\right)}$

onde $\mathrm{z}$ corresponde a um dia de observação qualquer.

\section{Eficiência da remoção de nitrogênio}

A eficiência da remoção de nitrogênio em um reator ANAMMOX pode ser calculada segundo a Eq. 9.

\section{NitRITAÇÃO PARCIAL ACOPLADA AO PROCESSO ANAMMOX}

O processo ANAMMOX transforma dois compostos nitrogenados: o íon amônio e o íon nitrito, em nitrogênio gasoso. Para que esta transformação seja realmente eficiente, a reação que ocorre neste processo deve seguir o balanço estequiométrico, que se apresenta na faixa de $1: 1,32$ (amônio:nitrito).

O processo SHARON (sistema de reator único para processo de conversão de altas concentrações de amônia em nitrito) é um dos novos processos de nitritação desenvolvidos. Este processo é conduzido a temperaturas na faixa de 35 a $40{ }^{\circ} \mathrm{Ce}$ pHentre 7 e 8 (Helinga et al., 1998).

O processo se diferencia do processo convencional por promover apenas uma nitrificação parcial do amônio até nitrito (nitritação). O sistema de nitrificação parcial é uma excelente alternativa para servir como pretratamento de um reator ANAMMOX. Na nitrificação parcial um efluente contendo apenas $\mathrm{NH}_{4}^{+}$, tem sua amônia parcialmente convertida a nitrito (Eq. 10), colocando o efluente em condição ideal para sua utilização em um sistema ANAMMOX (van Dongen et al., 2001; Kunz et al., 2007).

$$
\mathrm{NH}_{4}^{+}+0,75 \mathrm{O}_{2} \rightarrow 0,5 \mathrm{NO}_{2}^{-}+0,5 \mathrm{NH}_{4}^{+}+2 \mathrm{H}^{+}+\mathrm{H}_{2} \mathrm{O}
$$

A idéia de se acoplar o processo SHARON ao processo ANAMMOX, tem sido testada (Jetten et al., 1997) com sucesso em laboratório. O princípio de combinar os dois processos é o fato de que a amônia presente no efluente a ser tratado é 50\% oxidada a nitrito em um reator SHARON. O processo ocorre em condições limitadas de oxigênio dissolvido para que $50 \%$ da amônia sejam oxidados.

O processo combinado é eficiente para a remoção de nitrogênio de efluentes contendo altas concentrações de $\mathrm{NH}_{4}^{+}$ e baixas concentrações de matéria orgânica. Pode ser operado em dois reatores separados ou em apenas um reator (Khin \& Annachhatre, 2004). Com reatores separados tem-se a vantagem da facilidade do controle operacional e da otimização de cada processo.

\section{ANAMMOX NO BRASIL}

No Brasil, o estudo deste novo processo de tratamento não é apenas recente mas ainda é visto como desafio para sua aplicação real em águas residuárias, agropecuárias e agroindustriais, porém já existem alguns trabalhos que descrevem o uso de reatores ANAMMOX para o tratamento de amostras reais. Reginatto et al. (2005) desenvolveram um trabalho descrevendo a capacidade da biomassa de um reator de nitrificação-desnitrificação em tratar águas residuárias de esgoto doméstico para a remoção de nitrogênio pelo processo ANAMMOX. Araújo et al. (2010) também demonstraram enriquecimento de bactérias com atividade ANAMMOX a partir de lodo proveniente de esgoto doméstico de Belo Horizonte, MG, e reportaram a predominância de Candidatus Brocardia anammoxidans, após 6 meses de adaptação, utilizando alimentação sintética com concentrações de nitrogênio

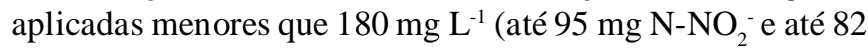
$\mathrm{mg} \mathrm{N}-\mathrm{NH}_{4}^{+}$).

Pesquisas visando à aplicação do processo ANAMMOX para o tratamento de efluentes da produção animal também vêm sendo estudadas. Kunz et al. (2007) lograram atividade ANAMMOX em uma amostra de lodo biológico coletado do tratamento de dejetos de suínos e aumentaram a população de bactérias pela aclimatação e imobilização, alimentando-as com um efluente sintético, para estimar a capacidade de remoção de nitrogênio. Como resultado, os autores perceberam que o lodo do sistema de tratamento de efluente da suinocultura foi uma excelente fonte de micro-organismos com atividade ANAMMOX.

Em estudos posteriores, Agnes et al. (2008), avaliaram aumento de carga e capacidade de remoção de nitrogênio de um meio de cultura sintético, por um reator contendo um meio polimérico não biodegradável em forma de rede em seu interior. O tempo de retenção hidráulico inicial foi de $24 \mathrm{~h}$ e a temperatura foi mantida em $35^{\circ} \mathrm{C}$. Os reatores estudados tiveram um fluxo

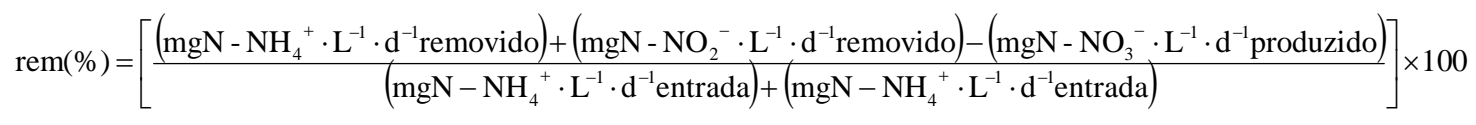


de alimentação contínuo e as cargas aplicadas sofreram aumento sempre que a concentração de nitrito e amônio na saída do reator se apresentava inferior a $30 \mathrm{mg} \mathrm{L}^{-1}$. As progressões de carga foram determinadas pelo aumento de vazão de alimentação do reator $\left(2,0\right.$ a $\left.18,0 \mathrm{~L} \mathrm{~d}^{-1}\right)$. Durante o período de estudo verificou-se boa capacidade de resposta de remoção da carga de nitrogênio aplicada ao reator, principalmente em vazões mais altas, com remoções acima de $80 \%$. A carga de nitrogênio removida pelos reatores de volume útil de 2 litros chegou a aproximadamente $2,3 \mathrm{~kg} \mathrm{de}^{-3} \mathrm{~d} \mathrm{~m}^{-1}$.

A presença de bactérias com atividade ANAMMOX foi confirmada por Viancelli et al. (2009), após análise de grânulos dos reatores estudados por Kunz et al. (2007) e Agnes et al. (2008), com inóculos obtidos de dejetos de suínos. Como já comentado, foi o primeiro estudo descrevendo a análise molecular da bactéria responsável pela atividade ANAMMOX que reportou diferenças filogenéticas da microbiota brasileira comparadas com as já descobertas em outras partes do mundo.

Kunz et al. (2008) investigaram uma forma de baixo custo para a remoção de amônia, com objetivo de aplicação em efluentes da suinocultura usando, para isto, o processo ANAMMOX. A eficiência de remoção de nitrogênio foi cerca de 5 vezes maior quando comparada com a dos processos de nitrificação-desnitrificação.

Recentemente, novos estudos com diferentes configurações (leito fluidizado e fluxo pistão) de reatores e concentrações crescentes de biomassa foram desenvolvidos por Casagrande et al. (2011b). Os autores reportaram elevada eficiência de remoção de nitrogênio quando utilizados cerca de $30 \%$ em volume de biomassa no reator e estabilização da atividade em apenas 62 dias.

Casagrande et al. (2011a), avaliaram a atividade ANAMMOX de um reator do tipo UASB submetido a altas cargas de nitrogênio e alcançaram a remoção de $18,3 \mathrm{~kg} \mathrm{de} \mathrm{N} \mathrm{m}^{-3} \mathrm{~d}^{-1}$ a um tempo de retenção hidráulica de 0,2 h.

\section{ConClusõEs}

1. O processo ANAMMOX é um dos processos mais eficientes de tratamento para remoção de nitrogênio e poderá, num futuro próximo e promissor, ser aplicado a efluentes agropecuários e agroindustriais. Ressalta-se a tendência de sua aplicação ao tratamento de águas residuárias com elevadas concentrações de nitrogênio em regiões com alta densidade de produção e baixa disponibilidade de áreas agricultáveis.

2. Devido à baixa velocidade de duplicação das células responsáveis pela atividade ANAMMOX, é necessário fazer, primeiro, a otimização das condições de operação e aclimatação dos micro-organismos, no reator.

3. Apesar de o processo ANAMMOX ser bastante promissor para o tratamento de efluentes, o desafio é adaptálo a afluentes agroindustriais, em função da necessidade bastante específica de substrato, ou seja, baixa concentração de carbono biodegradável, além de concentrações de $\mathrm{N}-\mathrm{NO}_{2}^{-}$e $\mathrm{N}-\mathrm{NH}_{4}^{+}$a uma proporção aproximada de 1:1.

4. O processo ANAMMOX pode ser conjugado com outros processos, melhorando ainda mais sua eficiência na remoção do nitrogênio. Processos como a nitrificação parcial, por exemplo, promovem um tratamento prévio e, assim, fornecem condições ótimas do efluente de entrada do ANAMMOX (afluente); desta forma, a eficiência de remoção de nitrogênio se torna maior. Uma possível alternativa é adaptá-lo ao tratamento de efluentes de biodigestores após nitritação parcial.

\section{LITERATURA CITADA}

Agnes, I. B.; Pra, J.; Kunz, A.; Steinmetz, R. Avaliação da capacidade de remoção de Nitrogênio por processo ANAMMOX em escala de bancada. In: Seminário de Desenvolvimento da Pesquisa, 12, 2008, Concórdia. Anais... Concórdia: UnC, 2008. CD Rom.

Ahn, Y-H. Sustainable nitrogen elimination biotechnologies: A review. Process Biochemistry, v.41, p.1709-1721, 2006.

Araújo, J. C.; Campos, A. P.; Correa, M. M. S; Silva, E. C.; von Sperling, M.; Chernicharro, C. A. L. Enriquecimento de bactérias anaeróbias oxidadoras de amônia - Anammox. Engenharia Sanitária e Ambiental, v.15, p.205-212, 2010.

Belli Filho, P.; Castilhos Jr, A. B.; Costa, R. H. R.; Soares, S. R.; Perdomo, C. C. Tecnologias para o tratamento de dejetos de suínos. Revista Brasileira de Engenharia Agrícola Ambiental, v.5, p.166-170, 2001.

Bolan, N. S.; Wong, L.; Adriano, D. C. Nutrient removal from farm effluents. Bioresource Technology, v.94, p.251-260, 2004.

Broda, E. Two kinds of lithotrophs missing in nature. Journal of Basic Microbiology, v.17, p.491-493, 1977.

Casagrande, C. G.; Kunz, A.; De Prá, M. C.; Perondi, T.; Soares, H. M. High-rate nitrogen removal using an Anammox column reactor. In: First International Anammox Symposium, 2011a, Kumamoto. Proceedings... Kumamoto: Kumamoto University, 2011a. p.107-112.

Casagrande, C. G.; Kunz, A.; Soares, H. M.; De Prá, M. C. Comparação da partida de reatores com atividade ANAMMOX com diferentes concentrações de inóculo. In: Simpósio Internacional sobre Gerenciamento de Resíduos das Produções Agropecuária e Agroindustrial, 2, 2011, Foz do Iguaçu. Anais... Foz do Iguaçu: SBERA, 2011b. CD-Rom

Chamchoi, N.; Nitisoravut, S.; Schmidt, J. E. Inactivation of ANAMMOX communities under concurrent operation of anaerobic ammonium oxidation (ANAMMOX) and denitrification. Bioresource Technology, v.99, p.3331-3336, 2008.

Dapena-Mora, A.; Fernández, I.; Campos, J. L.; MosqueraCorral, A.; Méndez, R.; Jetten, M. S. M. Evaluation of activity and inhibition effects on Anammox process by batch tests based on the nitrogen gas production. Enzyme Microbial Technology, v. 40, p.859-865, 2007.

De Pra, M. C.; Kunz, A.; Steinmetz, R.; Bortoli, M.; Casagrande, C. Acompanhamento da amonia live e ácido nitroso livre em um reator biológico aerado no tratamento de dejeto suíno. In: Congresso Sul Brasileiro de Produção Animal Sustentável 1, 2010, Chapecó. Resumos... Chapecó: UDESC, 2010. p.1-4. 
Egli, K.; Bosshard, F.; Werlen, C.; Lais, P.; Siegrist, H.; Zehnder, A. J. B.; van der Meer, J. R. Microbial composition and structure of a rotating biological contactor biofilm treating ammonium-rich wastewater without organic carbon. Microbial Ecology, v.45, p.419-432, 2003.

Hellinga C.; Schellen, A. A. J. C.; Mulder, J. W.; van Loosdrecht, M. C. M.; Heijnen, J. J. The SHARON process: An innovative method for nitrogen removal from ammonium rich wastewater. Water Science Technology, v.37, p.135-142, 1998.

Higarashi, M. M.; Kunz, A.; Mattei, R. M. Aplicação de adsorção para remover amônia de efluentes suinícolas pré-tratados. Química Nova, v.31, p.1156-1160, 2008.

Hussain, S.; Aziz, H. A.; Isa, M. H.; Adlan, M. N; Asaari, F. A. H. Physico-chemical method for ammonia removal from synthetic wastewater using limestone and GAC in batch and column studies. Bioresource Technology, v.98, p.874-880, 2006.

Isaka, K.; Date, Y.; Sumino, T.; Yoshie, S.; Tsuneda, S. Growth characteristic of anaerobic ammonium-oxidizing bacteria in an anaerobic biological filtrated reactor. Biotechnological Products and Process Engineering, v.70, p.47-52, 2006.

Jetten, M. S. M.; Cirpust, I.; Kartal., B.; van Niftrik, L.; van de Pas-Shoonen, K. T.; Sliekers, O.; Haaijer, S.; van der Star, W.; Schmid, M.; van de Vossenberg, J.; Schmidt, I.; Harhangi, H.; van Loosdrecht, M.; Kuenen, J. G.; Den Camp, H. O.; Strous, M. 1994-2004: 10 years on the anaerobic oxidation of ammonium. In: Nitrogen Cycle Meeting, 10, 2004, Norwich. Anais... Norwich: University of East Anglia 2004. p.119-123.

Jetten, M. S. M.; Horn, S. J.; van Loosdrecht, M. C. D. Towards a more sustainable municipal wastewater treatment system. Water Science and Technology, v.35, p.171-180, 1997.

Jetten, M. S. M.; Strous, M.; van de Pas-Shoonen, K. T.; Schalk, J.; van Dongen, U. G. J. M.; van de Graaf, A. A.; Logemann, S.; Muyzer, G.; van Loosdrecht, M. C. M.; Kuenen, J. G. The anaerobic oxidation of ammonium. FEMS Microbiology Reviews, v.22, p.421-437, 1999.

Jetten, M. S. M.; Wagner, M.; Fuerst, J.; van Loosdrecht, M.; Kuenen, G.; Strous, M. Microbiology and application of the anaerobic ammonium oxidation ('anammox') process. Current Option Biotechnology, v.12, p.283-288, 2001.

Kartal, B.; Rattray, J.; van Niftrik, L. A.; van de Vossenberg, J.; Schmid, M. C.; Webb, R. I.; Schouten, S.; Fuerst, J. A.; Damsté, J. S.; Jetten, M. S. M.; Strous, M. Candidatus "Anammoxoglobus propionicus" a new propionate oxidizing species of anaerobic ammonium oxidizing bacteria. Systematic and Applied Microbiology, v. 30, p.39-49, 2007.

Khin, T.; Annachhatre, A. P. Novel Micobial nitrogen removal processes. Biotechnology Advances, v.22, p.519-532, 2004.

Kuenen, J. G. Anammox bacteria: From discovery to application. Nature, v.6, p.320-326, 2008.

Kunz, A.; Miele, M.; Steinmetz, R. L. R. Advanced swine manure treatment and utilization in Brazil. Bioresource Technology, v.100, p.5485-5489, 2009.

Kunz, A.; Steinmetz, R.; Vanotti, A. S.; Soares, H. M. Development of a New Generation Low Cost Treatment of Ammonia for Livestock Effluents Using Anammox and Nitritation. In: $13^{\text {th }}$ RAMIRAN International Conference, 2008, Albena. Proceedings... Albena: FAO, 2008. p.255-258.
Kunz, A.; Vanotti, M.; Szogi, A.; Gonzales, M. C. G.; Schierholt Neto, G. F.; Soares, H. M. Development of Anammox process for animal waste treatment: Experiences in Brazil. In: International Symposium on Air Quality and Waste Management for Agriculture, 2007, Broomfield. Proceedings... Broomfield: ASABE, 2007. CD Rom.

Kuypers, M. M.; Sliekers, A. O.; Lavik G.; Schmid, M.; Jorgensen, B. B.; Kuenen, J. G.; Sinninghe Damsté, J. S.; Strous M.; Jetten, M. S. M. Anaerobic ammonium oxidation by anammox bacteria in the Black Sea. Nature, v.422, p.608611, 2003.

Milan, Z.; Sánchez, E.; Weiland, P.; Lãs Pozas, C.; Borja, R.; Mayari, R.; Ravirosa, N. Ammonia removal from anaerobically treated piggery manure by ion exchange in columns packed with homoionic zeolite. Chemical Engineering Journal, v.66, p.65-71, 1997.

Ni, S. Q.; Fessehaie, A.; Lee, P. H.; Gao, B. Y.; Xu, X.; Sung, S. Interaction of anammox bacteria and inactive methanogenic granules under high nitrogen selective pressure. Bioresource Technology, v.101, p.6810-6915, 2010.

Quadros, D. G.; Oliver, A. P. M.; Regis, U.; Valladares, R.; Souza, P. H. F.; Ferreira, E. F. Biodigestão anaeróbia de dejetos de caprinos e ovinos em reator contínuo de PVC flexível. Revista Brasileira de Engenharia Agrícola Ambiental, v.14, p.326332, 2010.

Pastor, L.; Marti, N.; Bouzas, A.; Seco, A. Sewage sludge management for phosphorus recovery as struvite in EBPR wastewater treatment plants. Bioresource Technology, v.99, p.4817-4824, 2007.

Pergher, S. B. C.; Caovilla, M.; Detoni, C.; Machado, C. Remoção de $\mathrm{Cu}^{+2}$ de soluções aquosas em zeólita $\mathrm{NaX}$. Efeito da granulometria. Química Nova, v.28, p.397-401, 2005.

Reginatto, V.; Teixeira, R. M.; Pereira, F.; Schmidell, W.; Furigo Jr, A.; Menes, R.; Etchebehere, C.; Soares, H. M. Anaerobic ammonium oxidation in a bioreactor treating slaughterhouse wastewater. Brazilian Journal of Chemical Engineering, v. 22, p.593-600, 2005.

Richards, F. A. Anoxic basins and fjords. Chemical Oceanography, v.1.p.611-645, 1965.

Schierholt Neto, G. F. Desenvolvimento de uma flora de microrganismos oxidadores anaeróbios de amônia utilizando inóculos provenientes de dejeto de suíno. Florianópolis: UFSC, 2007. 116p. Dissertação Mestrado

Sittig, M.; Schlesner, H. Chemotaxonomic investigation of various prosthecate and/or budding bacteria. Systematic and Applied Microbiology, v.16, p.92-103, 1993.

Strous, M.; van Gerven, E.; Kuenen, G.; Jetten, M. Effects of Aerobic and Microaerobic Conditions on Anaerobic Ammonium-Oxidizing (Anammox) Sludge. Applied and Environmental Microbiology, v.63, p.2446-2448, 1997a.

Strous, M.; van Gerven, E.; Kuenen, M. S. M. Ammonium removal from concentrated waste streams with the anaerobic ammonium oxidation (Anammox) process in different reactor configurations. Water Research, v.31, p.1955-1962, 1997b.

Strous, M.; Heijnen, J. J.; Kuenen, J. G.; Jetten, M. S. M. The sequencing batch reactor as a powerful tool for the study of slowly growing anaerobic ammonium-oxidizing microorganisms. Applied Microbiology Biotechnology, v.50, p.589-596, 1998. 
Strous, M.; Fuerst, J. A.; Kramer, E. H. M.; Logemann, S.; Muyzer G.; van de Pas-Schoonen, K. T.; Webb, R.; Kuene, J.; Jetten, M. S. M. Missing litotroph identified as new planctomycete. Nature, v.400, p.446-449, 1999b.

Strous, M.; Kuenen, J. G.; Jetten, M. S. M. Key physiology of anaerobic ammonium oxidation. Applied and Environmental Microbiology, v.65, p.3248-3250, 1999a.

Tang, C. J.; Zheng, P.; Wang, C. H.; Mahmood, Q.; Zhang, J. Q.; Chen, X. G.; Zhang, L.; Chen, J. W. Performance of highloaded ANAMMOX UASB reactors containing granular sludge. Water Research, v.45, p.135-144, 2011.

van De Graaf, A. A.: Brujin, P.; Robertson, L. A.; Jetten, M. S. M.; Kuenen, J. G. Autotrophic growth of anaerobic ammonium-oxidizing micro-organisms in a fluidized bed reactor. Microbiology, v.142, p.2187-2196, 1996.

van De Graaf, A. A.; Brujin, P.; Robertson, L. A.; Jetten M. S. M.; Kuenen, J. G. Metabolic pathway of anaerobic ammonium oxidation on the basis of ${ }^{15} \mathrm{~N}$ studies in a fluidized bed reactor. Microbiology, v.143, p.2415-2421, 1997. van Dongen, U.; Jetten, M. S. M.; van Loosdrecht, M. C. M. The SHARON ${ }^{\circledR}$-Anammox ${ }^{\circledR}$ process for treatment of ammonium rich wastewater. Water Science and Technology, v.44, p.153-160, 2001.

Viancelli, A.; Kunz, A.; Esteves, P. A.; Nishiyama, T.; Fujii, T.; Vanotti, M.; Antonio, R. V. Analysis of bacterial community from a sludge reactor with Anammox activity. In: I International Symposium on Animal Waste Management SIGERA, 2009, Florianópolis. Proceedings... Florinópolis: SBERA, 2009. CD Rom.

Vivan,M.; Kunz, A.; Stolberg, J.; Perdomo, C.; Techio, V. H. Eficiência da interação biodigestor e lagoas de estabilização na remoção de poluentes em dejetos de suínos. Revista Brasileira de Engenharia Agrícola Ambiental, v.14, p.320-325, 2010.

Zhang, L.; Zheng, P.; Tang, C.; Jin, R. Anaerobic ammonium oxidation for treatment of ammonium-rich wastewaters. Journal of Zhejiang University Science B, v.9, p.416-426, 2008.

Zhu, G; Peng, Y.; Li, B.; Guo, J.; Yang, Q.; Wang, S. Biological removal of nitrogen from wastewater. Reviews Environmental Contamination \& Toxicology, v.192, p.159-195, 2008. 